\author{
Cadernos de \\ ESTUDOS LINGï̈ISTICOS - (55.2), Campinas, Jul./Dez. 2013
}

\title{
A PROPÓSITO DA VIOLÊNCIA NA LINGUAGEM
}

\author{
DANIEL DO NASCIMENTO E SILVA* \\ CLAUDIANA NOGUEIRA DE ALENCAR**
}

\begin{abstract}
RESUMO: Este artigo apresenta um panorama do problema da violência nos estudos sobre a significação. Apontamos que a violência não é um traço acidental no uso da língua: a violência tanto oblitera o significado quanto gera, talvez como efeito perlocucionário, novas possibilidades de significação. $\mathrm{O}$ artigo propõe inicialmente uma crítica à posição vitalista nos estudos da linguagem. Em seguida, o trabalho propõe, numa visada pragmática, uma definição para violência linguística. Chamamos de violentos os usos linguísticos que posicionam o outro - especialmente aquele que representa a raça, o gênero, a sexualidade e o território que não se quer habitar - num lugar vulnerável. Trata-se de usos que atingem o sujeito em seu ponto mais frágil, a sua condição. O artigo finalmente analisa a mediação de um caso recente de crime de racismo, uma instância de uso violento da língua.

PALAVRAS-CHAVE: violência linguística, vitalismo, atos de fala.
\end{abstract}

\begin{abstract}
This paper offers an overview of the problem of violence in the studies of signification. We point out that violence is not some accidental feature of language use: violence not only obliterates meaning, but also engenders, probably as a perlocutionary effect, new possibilities of signification. The article initially critiques the vitalist position in language studies. It then proposes, from a pragmatic perspective, a definition for linguistic violence. We call violent those language uses that position the other - especially the one who represents the race, the gender, the sexuality and the territory one does not want to inhabit - in a vulnerable place. Such utterances hit the subject in her most fragile point, her human condition. The paper finally analyzes the mediation of a recent case of racism in Brazilian court. KEYWORDS: linguistic violence, vitalism, speech acts.
\end{abstract}

\section{INTRODUÇÃO}

É um truísmo afirmar que a linguagem é um aspecto central da condição humana. Por outro lado, postular um lugar para a violência em nossa condição de sujeitos falantes de uma língua natural não é algo tranquilo. Por exemplo, se observarmos no campo da pragmática linguística a atenção ao fenômeno de linguagem rotulado de 'polidez' em detrimento da sua contraparte, por assim dizer, negativa, a 'impolidez', podemos perceber que há uma inclinação muito maior para a investigação de interações pacíficas e não-conflituosas. A noção clássica de polidez, tal como formulada por Brown \& Levinson (1987 [1978])

*dnsfortal@gmail.com

** claunoce@gmail.com 
e Leech (1983), privilegia os aspectos harmoniosos da interação linguística e endossa o princípio griceano de que o propósito primeiro dos falantes é cooperar. Desses 30 anos que nos separam da formulação do conceito de polidez, pouca atenção tem sido devotada para os tipos de interação não-cooperativas. Uma quantidade imensa de pesquisas têm sido feitas sob a égide da polidez, gerando demanda inclusive para a criação de um periódico específico, o Journal of Politeness Research. Apenas recentemente, no entanto, um número modesto de pesquisadores passou a investigar os momentos em que a linguagem é usada não para cooperar, mas para causar dano (cf. Bousfield, 2008; Bousfield \& Locher, 2008; Culpeper, 2011). Em livro recente sobre a impolidez, Culpeper (2011:6) afirma que as abordagens clássicas da polidez "tendem a dar a ideia de que a impolidez é um tipo de falha pragmática, uma consequência de não se fazer algo, ou meramente um comportamento anormal, indigno de consideração".

Gostaríamos de argumentar que a visão de que fenômenos como a impolidez - dentre outros que fazem parte da violência na linguagem - são 'anormais' é licenciada por aquilo que Peng Cheah (1999) chama de 'ontologia vitalista'. Essa ontologia fundamenta vários modos de pensar a linguagem, o sujeito e a modernidade. Dentro do esquema biogenético da ontologia vitalista, a vida é oposta à morte, o presente ao passado, o espírito à matéria e "a atualidade concreta viva à forma abstrata fantasmagórica” (Cheah, 1999:227). A própria ideia de modernidade, sustenta Cheah, se assenta no pressuposto de que esse modo de governar as subjetividades garante aos indivíduos a conquista de um futuro pensado "como eterna vida presente" (p.227). No discurso nacionalista, “a nação não é apenas concebida em analogia a um ser orgânico vivo, mas é tida também como meio ou substrato permanente por meio do qual se garante aos indivíduos uma certa vida além da forma finita ou meramente biológica de vida e, portanto, além da mortalidade e da morte" (id.ibid.). Fenômenos como 'violência', 'pobreza', 'fanatismo', 'subordinação' seriam estranhos a essa ontologia - eles fazem parte do passado vencido pela nação moderna. Em resumo, a ontologia vitalista coloca de um lado vida e futuro, dois elementos que fundam o sujeito moderno e garantem a sua existência, e do outro, morte e passado, traços da matéria inorgânica que pode (e deve) ser deixada para trás.

O problema é que a violência não é traço acidental da vida urbana e social no Brasil. E, embora o crime violento em cidades como São Paulo e Rio de Janeiro seja superior ao de outras metrópoles do Globo Norte (cf. Caldeira, 2000; Adorno, 2011), outros tipos de sociabilidades violentas se instituem nas grandes cidades de países ditos desenvolvidos, como atestam toda a violência terrorista pós 11 de Setembro, os tiroteios em escolas, os protestos violento de minorias, os confrontos sangrentos entre manifestantes e polícia devido às mudanças no trabalho e na educação etc. $\mathrm{O}$ que essa co-ocorrência da violência com o quadro moderno da nação atesta é que, ao invés de um 'acidente', a violência é um aspecto central de nossa condição humana - 'assim como a rejeição à violência', como bem lembram Nancy Scheper-Hughes e Philippe Bourgois (2004). No quadro de teorias sobre a língua e sobre o sujeito que rejeitam a ontologia vitalista, percebe-se que a violência aparece entre as condições de possibilidade para diversas instâncias de nossa relação com a vida social, como 
a construção de narrativas (Briggs, 2007a), a invenção e o desdobrar temporal de certas tradições (Asad, 2008), a definição do que seja um autor (Foucault, 1998 [1969]) e a própria constituição da subjetividade (Freud, 1930 e Butler, 1997).

Neste artigo, discutiremos o papel central da constituição, produção e comunicabilidade da violência no uso da língua. Entendemos essa discussão como um convite a que a pragmática linguística e outras abordagens críticas incluam a questão da violência e do conflito em sua agenda de pesquisa. No que se segue, apontaremos como a ontologia vitalista opera nos estudos da linguagem, selecionando, para tanto, dois estudos sobre o uso de palavras positivas e negativas nas línguas do mundo. Em seguida, apresentamos o que entendemos ser a violência linguística. Oferecemos então um modelo de análise da violência na linguagem, mais especificamente sobre a mediação de um processo de crime de racismo movido pela $\mathrm{OAB} / \mathrm{PE}$ contra a estudante de direito paulista Mayara Petruso, que em 2010 manifestou ódio contra os nordestinos em suas contas de Twitter e Facebook.

\section{VITALISMO EM LINGUÍSTICA}

Como afirmamos na seção anterior, a ontologia vitalista opõe o espírito à matéria ou ao mecanismo. Com Derrida (1973), entendemos que dicotomias não são meras oposições, mas hierarquias em miniatura. Assim, a racionalidade do sujeito moderno, aquele que comparece como o falante das línguas naturais em muitas teorias, depende do valor superior que é dado ao espírito em detrimento da matéria. No quadro do pensamento sobre a linguagem, essa dicotomia opera na forma daquilo que Wittgenstein (1953), em sua segunda filosofia, chamou de 'sublimação dos conceitos'. No sentido químico, a sublimação é a passagem de uma substância do estado sólido para o gasoso. Wittgenstein aponta que é essa passagem que ocorre quando se postula que um processo mental abstrato e oculto acompanha atividades linguísticas como 'compreender', por exemplo. Opera-se aí uma passagem da concretude da prática comunicativa para uma abstração ou espiritualização. Como aponta o filósofo:

\footnotetext{
E fazemos aqui o que fazemos em mil outros casos similares: já que não podemos especificar nem mesmo uma ação corpórea a que chamamos apontar para a forma (em oposição, por exemplo, à cor), dizemos que uma atividade espiritual [mental, intelectual] corresponde a essas palavras.

Onde nossa linguagem sugere um corpo e não há nenhum: lá, nos apraz dizer, está um espírito. (Wittgenstein, 1953, §36)
}

Central para a dicotomia espírito/matéria é a própria disjunção entre mente humana e mecanismo proposta por Descartes e Newton. A matéria, nesse modelo, segue leis da natureza, sendo a mente humana dotada do poder racional de compreender essas leis. Comenta Cottinghan (1995:95) que estes são, na verdade, os dois princípios fundamentais na ciência cartesiana: "primeiro, que o universo funciona de acordo com certas leis imutáveis estabelecidas por Deus, e, segundo, 
que a mente humana tem a capacidade inata, concedida por Deus, de descobrir a estrutura dessas leis." A linguagem humana, por exemplo, não poderia derivar da contingência da interação do corpo com a natureza, na medida em que ela, a linguagem, seria o produto da mente racional. É essa concepção de racionalidade que subjaz ao princípio da lógica da conversação, postulado por Grice (1975). Vejamos como esse princípio racional de uso da língua é refraseado por Levinson (1983:103), num dos primeiros manuais introdutórios à pragmática:

Grice sugere as máximas são de fato não convenções arbitrárias, mas descrevem, ao contrário, meios racionais para conduzir trocas cooperativas. Se é assim, então deveríamos esperar que elas também governam aspectos do comportamento não-linguístico, e elas de fato parecem fazer isso (ênfase acrescida).

Nos termos da ontologia vitalista, a capacidade racional humana de entender e dominar o mundo natural (ou, nos termos de Levinson, de conduzir atos linguísticos e não-linguísticos) é o que garante o domínio sobre o inorgânico e sobre a morte. Como defende Cheah (1999:230), no pensamento sobre a nação, "a organização política, na medida em que torna a natureza matéria orgânica/ organizada ao imbuí-la de vitalidade e propósito que excede o mecanismo, e na medida em que a organização política é uma forma de atualização e objetificação de ideias racionais pela vontade intencional, então ela seria um exorcismo e suspensão da morte".

De forma a criticarmos a presença dessa ontologia em outros trabalhos em linguística, discutiremos aqui traços do vitalismo em dois estudos sobre o uso de palavras positivas e negativas. Trata-se do artigo "Naming on the bright side of life", publicado por Michael Kelly na revista Names em 2000 e do artigo "Negativity bias in language: A cognitive-affective model of emotive intensifiers", publicado por Zhuo Jing-Schmidt na prestigiada Cognitive Linguistics, em 2007. Enquanto Kelly defende que palavras positivas são mais frequentes do que palavras negativas nas línguas do mundo, o que, de acordo com o autor, mostra a instanciação de uma "visão otimista da vida" (Kelly, 2000:48), Jing-Schmidt (2007:418,424) defende o argumento oposto de que prestamos "significativamente mais atenção à informação desagradável do que à agradável”, i.e., em nossa "realidade subjetiva universal" existe um aparato cognitivo-afetivo chamado de inclinação à negatividade [negativity bias], um componente vital do nosso comportamento adaptativo que é refletido na língua (Jing-Schmidt, 2007:425).

A adesão ao vitalismo é ubíqua na reflexão de Kelly. A felicidade, em seu trabalho, está no cerne da fala humana: "[e]mbora poucos de nossos dias transbordem de alegria, nós mesmo assim passamos a maior parte do tempo navegando no lado feliz da vida. Assim, dizemos 'lindo' mais do que 'feio' porque a beleza é, felizmente, mais comum" (p.5). O autor acrescenta que a motivação para isso não deve ser econômica, porque "a fala otimista aparece nas línguas ao redor do mundo apesar da grande variação das generosidades da vida” (id.ibid.). 
Kelly nega uma correlação natural entre riqueza material e inclinação ao positivo, mas não exclui essa possível causa para o uso das palavras positivas, sem lamentar que os Estados Unidos não detenham as mais altas taxas de otimismo lingüístico na geopolítica da felicidade:

Palavras positivas são usadas mais frequentemente do que palavras negativas em línguas e culturas tão diversas como chinês, finlandês e turco. Há alguma variação na força do efeito, mas ele não pode ser inferido por mensurações da riqueza material. Os Estados Unidos, por exemplo, são a nação mais rica da história da humanidade, mas a tendência americana a usar mais palavras positivas do que negativas não é equivalentemente grande. De fato, a inclinação ao positivo no inglês é relativamente pequena se comparada com outras línguas, inclusive aquelas cujos falantes têm sido historicamente empobrecidos (idem).

Os Estados Unidos ocupam nesse discurso o lugar prototípico do progresso. "[A] mais rica nação da história da humanidade" é, em outras palavras, a nação que superou as sombras de um passado que subsiste em outras nações "cujos falantes têm sido historicamente empobrecidos". Essa diferenciação vitalista é ecoada em sua discussão do realismo nominal, a crença de que "um símbolo carrega a essência do seu referente, uma essência que pode ser transferida a qualquer objeto assim nomeado" (p.7). O autor cita um pioneiro da antropologia, James George Frazer, para quem "o homem primitivo toma o seu nome como uma porção vital de si mesmo e cuida do nome nesses termos" (Frazer, 1951, apud Kelly, 2000:7). Kelly acrescenta que Piaget também atribuiu esse modo de pensar às "mentes de crianças" (id.ibid.). Essa forma primitiva de conhecer, que habita o sujeito moderno apenas quando este é uma criança e portanto não foi capaz de adquirir a agência para superar essa condição, é contrastada com estudos de nomes "na literatura filosófica ocidental" que enfatizam "a arbitrariedade essencial do elo entre nome e referente" (p.8). Embora o linguista reconheça que os padrões de nomeação americanos sejam calcados fortemente no realismo nominal, o autor faz o comentário iluminista de que "[n]os serenos momentos de cognição clarificada, podemos rejeitar o realismo nominal e relegar seu poder mágico a mentes simples e infantis" (id.ibid.).

Se a invocação de um passado pavoroso no trabalho de Kelly é correlacionada com a persistência de modos de pensamento em mentes "primitivas" e "simples" ou com a possibilidade de que mentes "infantis" têm de caber no organicismo teleológico de seu discurso, no trabalho de Jing-Schmidt ela é feita em nome da evolução biológica. Nos termos da autora, o mau é mais saliente cognitivamente, i.e., demanda mais atenção do que o bom porque "sinaliza para a necessidade de mudança que geralmente aumenta a adaptabilidade evolutiva" (Jing-Schmidt, 2007:419). O vocabulário do bom e do mau, no artigo da autora, segue o léxico vitalista do prazer e do triunfo sobre a morte. "Por 'bom' entendemos os resultados desejáveis, benéficos ou agradáveis, inclusive estados e consequências. O 'mau' é o oposto: indesejável, perigoso ou desagradável" (Baumeister et al., apud Jing- 
Schmidt, 2007:418). Ela argumenta que o princípio fundacional da inclinação à negatividade é tanto "automático" (p.419) quanto "universal" (p.424), uma estratégia de sobrevivência que, em última instância, nos faz "mobilizar melhor nossa atenção e outros recursos corpóreos para evitar riscos potenciais" (p.420).

A teleologia em ambos os discursos é clara: seja a tendência humana orientada a atribuir saliência cognitiva a palavras positivas (nos termos de Kelly) ou a palavras negativas (nos termos de Jing-Schmidt), os modos de subjetividade liberais são a última palavra, aquela que irá iluminar a sombra da morte, interpretada ora nos termos de uma mente primitiva ou de sociabilidades nãoocidentais, ora nos termos de coisas ou eventos desagradáveis. Violência, dor e medo apenas comparecem nessas duas abordagens na medida em que podem ser suplantados pela busca do prazer. E é justamente a busca do prazer a questão fundamental do sujeito moderno. Talal Asad (2003:71) sumaria bem a promessa do discurso moderno, e que parece ser endossada tanto por Levinson quanto por Kelly e Jing-Schmidt:

Dada a liberdade essencial ou soberania natural do sujeito humano, e dados também seus próprios desejos e interesses, o que os seres humanos devem fazer para realizarem sua liberdade, empoderarem-se e escolherem o prazer?".

Contrariamente a essa visão liberal, queremos defender aqui que é possível olhar para a língua e para o sujeito fora do esquema biogenético da ontologia vitalista. Ao compreendermos a permanência da violência e de outras sensibilidades e sociabilidades não-liberais, como a dor, a subordinação e a própria tristeza, é possível compreender fenômenos que são tidos de partida como "anormais", tal como alerta Culpeper (2011) no que diz respeito à impolidez. Avancemos.

\section{VIOLÊNCIA LINGUÍSTICA: EM TORNO DE UMA DEFINIÇÃO}

Certas expressões da língua, como sabemos, dependem de um contexto para serem interpretadas. Expressões indiciais do português como 'aqui', 'eu' e 'você' só fazem sentido se atribuídas a um lugar específico ou a pessoas definidas, o que só ocorre em um contexto concreto de uso. Em que medida essa dependência do contexto se aplica a outras formas da língua? Haveria significados literais que independam de um contexto? Significados violentos são imanentes à língua? Estas são perguntas a que muitos linguistas, filósofos e antropólogos têm se dedicado ao longo dos anos. Ao passo que, para alguns estudiosos, seguindo a esteira dos estudos de Grice (1989), haveria uma porção do significado que depende da língua e outra porção que depende do contexto, adotamos, no presente estudo, a visão de que não há significados que independam de um contexto de uso.

Ao lado de alguns trabalhos em linguística cognitiva (Lakoff, 1987) e antropologia linguística (Hanks, 1996), partimos da premissa de que "o significado - mesmo o sentido literal - deriva de uma fusão da forma linguística com o contexto" (Hanks, 1996:232). Nesse sentido, o significado não reside no "interior" da língua, encapsulado em expressões linguísticas per se; ao contrário, o significado é algo que "emerge" da "interação entre a língua e suas circunstâncias" (Hanks, 1996, 
p.268). Todo fato linguístico, a partir dessa visão, passa a ser percebido como um fato indexical (Silverstein, 2003). Ou seja, toda forma linguística refere-se tanto às condições envolventes de sua própria produção quanto à ordem macrossocial maior.

Se não há significados imanentes à língua, que peso atribuir aos significados das palavras que ferem, machucam, paralizam? Esses significados seriam dependentes somente de um contexto violento, sendo indiferente a forma linguística empregada? A discussão em torno do uso politicamente correto das palavras parece indicar que há palavras "mais carregadas" que outras, a implicação disso sendo que certos significados parecem ser quase sempre violentos, independente de seus contextos de uso. Ao defender o conceito da linguagem politicamente correta, Rajagopalan (2000: 98) afirma que, por exemplo, "banheiro ou lavabo fede muito menos que latrina, uma garota de programa escandaliza muito menos as sensibilidades, descansar no Senhor dói menos do que morrer ou bater as botas".

O caso da luta política por palavras mais afirmativas, em que certas expressões socialmente violentas passam a ser desautorizadas por aqueles que lutam por uma nova ética do dizer, não invalida a tese de que o significado emerge da relação língua/circunstâncias de uso. Os contextos de uso não podem ser vistos como cenas isoladas de um eterno presente, onde dois ou mais indivíduos intencionais interagem; os contextos são, ao contrário, atos históricos e sociais onde dois ou mais agentes sociais interagem por meio da linguagem. $\mathrm{O}$ que tais agentes sociais pronunciam não são propriamente palavras, "carregadas" de significado violento ou não, mas "atos de fala" (Austin, 1962), que funcionam (ou falham) precisamente porque "ecoam ações prévias” (Butler, 1997:51). Esses contextos de uso são tipificados (Bourdieu, 1991) ou ritualizados (Derrida, 1977), evocando poder, afeto e adesão entre os agentes sociais. Nesse sentido, dizer que alguém 'nos deixou prematuramente' dói menos que dizer que essa pessoa 'bateu as botas cedo' porque o primeiro uso, à diferença do segundo, ao ser enunciado numa cena ritual, ecoa ou tipifica um relacionamento de respeito, de fundo religioso ou moral, entre quem fala e a pessoa que faleceu.

A ritualização ou tipificação da experiência humana se atualiza, então, no modo mais ou menos convencionalizado ou genérico em que empregamos os recursos da língua em situações de uso. William Hanks aponta que os usuários da língua, para se comunicarem, não precisam necessariamente partilhar da mesma gramática, "mas precisam partilhar, em certa medida, modos de se orientar no contexto social" (Hanks, 1996:235). Segundo o autor, os usuários da língua não baseiam sua prática linguística numa gramática auto-contida na língua, que independe dos mundos sociais de que participam; ao contrário, a habilidade de se comunicar depende, em grande medida, "de como os agentes se situam em relação aos outros e a seus contextos" (ibidem, p.237). A prática linguística pressupõe, assim, uma "orientação" social.

Parte do que Hanks chama de "orientação" consiste "na predisposição dos agentes de perceber e agir de certos modos" (ibidem, p.237). Essa orientação tem a ver com o que Bourdieu (1991) chama de habitus, um conceito que evidencia o modo em que rotineira e convencionalmente nos engajamos na ação, algo 
que fazemos também por meio de rotinas corpóreas (lembremos do 'hábito' das freiras, que indica certos modos de usar o corpo). Gostaríamos de chamar atenção para o fato de que a violência da linguagem, provavelmente devido à natureza destruidora da própria violência em si, oblitera precisamente a orientação contextual e corpórea em que baseamos nossa prática comunicativa. Nos termos de Judith Butler (1997:4), "ser ferido pela fala é sofrer uma perda de contexto, isto é, não saber onde se está" (ênfase acrescida). Nesse sentido, o nosso interesse no presente texto é entender precisamente a violação daquilo que Hanks postula como constitutivo de nossa ação na linguagem, isto é, a orientação contextual. Vejamos o que Butler acrescenta em relação a essa desorientação contextual de que estamos falando:

Ser chamado injuriosamente é não apenas ser colocado diante de um futuro desconhecido, mas não saber o tempo e o lugar da injúria, além de sofrer a desorientação de sua própria situação como o efeito dessa fala. Exposta no momento de tal despedaçamento está precisamente a volatilidade do lugar do sujeito dentro da comunidade dos falantes; o falante pode "ser colocado em seu lugar" por essa fala, mas tal lugar pode ser um não-lugar (id.ibid.).

Como veremos a seguir, a obliteração do lugar que o usuário ocupa na comunidade dos falantes pode significar, para além do despedaçamento e do nãolugar de que trata Butler, uma forma de agência que se dá na borda das "arestas vacilantes da legitimidade na fala" (Butler, 1997:41). A mesma linguagem que fere oferece possibilidades de existência linguística ao sujeito. Assim, a violência na linguagem pode ser vista como algo que não só destrói a identidade do sujeito e a própria significação, mas também as constitui.

Como definir, então, isso que temos chamado de "violência linguística"? Entendemos que qualquer definição que venha a ser atribuída a este tipo de violência partirá da premissa de que a linguagem é um modo de ação. Postular que a linguagem viola o corpo ou uma estrutura de afetos implica afirmar que a linguagem não é mera representação de eventos ou situações no mundo, mas uma forma de agir, no caso, violentamente. Tomamos aqui uma possibilidade inscrita no próprio conceito ordinário de 'injuriar' no português e em outras línguas: lê-se no dicionário Houaiss que "injuriar" é tanto fazer 'injúria verbal' ou 'insultar' quanto 'causar dano, estrago ou lesão'. De acordo com a hipótese de Grady (1997), há correlação cognitiva entre 'harm' (como experiência afetiva de insulto) e 'physical injury' (como injúria física), expressa na forma da metáfora conceitual HARM IS PHYSICAL INJURY, o que, de acordo com o autor, seria derivado da correlação entre o dano físico, que é uma experiência física, e a resposta afetiva do tipo infelicidade ou mal-estar (dentre tantas outras), que está no nível das experiências emocionais e co-ocorre com o dano físico (Grady, 1997:295, cf. Lima, 1999 e Gibbs, Lima e Françozo, 2004). Embora nosso trabalho não seja em medida alguma uma incursão cognitiva, cremos ser válido olhar para esse tipo de metáfora, que motiva expressões como 'aquelas palavras foram uma punhalada no meu peito' ou ‘fiquei engasgado com o que escutei’.

Assim, numa visada pragmática, chamamos de violentos os usos linguísticos que, ao posicionarem o outro - especialmente aquele que representa a raça, o 
gênero, a sexualidade e o território que não se quer habitar - num lugar vulnerável, acabam por insultar, injuriar ou violar a sua condição. Entendemos ser este um fato situado, em que certos recursos da língua são empregados para ferir. Dito de outro modo, quando um sujeito ou grupo de sujeitos usa a língua para diminuir, depreciar, desdenhar ou abominar um grupo social ou um indivíduo específico, ele ou ela está usando a língua violentamente, i.e., está afetando uma estrutura de afetos que se sustenta na linguagem. O racismo, por exemplo, quando expresso linguisticamente, é uma instanciação da violência na linguagem. Ofereceremos uma análise de um caso recente de racismo para ilustrar a questão.

\section{USANDO A LÍNGUA PARA CAUSAR DANO}

Em 2010, a Ordem dos Advogados do Brasil, Seção Pernambuco instaurou um processo de crime de racismo e de incitação pública ao crime de homicídio contra a estudante de direito Mayara Penteado Petruso ${ }^{1}$. Na ocasião da eleição de Dilma Rousseff, candidata do PT à presidência da república, Mayara postou algumas mensagens em suas contas do Twitter e Facebook, manifestando ódio contra aqueles que teriam eleito Dilma. A seguir, uma captura de tela de seu Twitter:

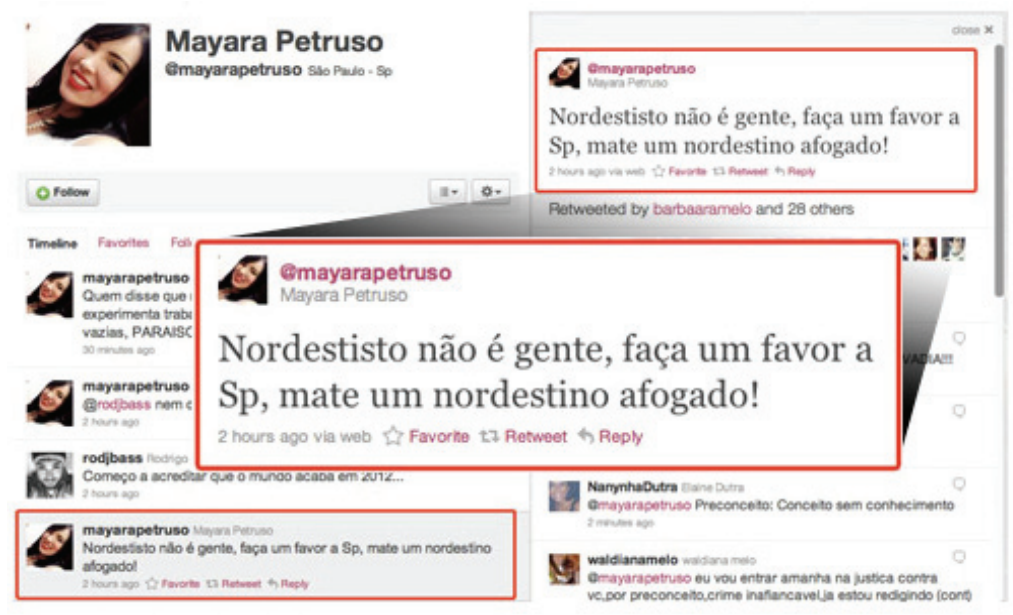

Figura 1 - Twitter de Mayara Petruso (apagado após a polêmica)

Como se vê pela figura, a estudante diz textualmente que "Nordestisto (sic) não é gente, faça um favor a SP, mate um nordestino afogado". O enunciado violento em questão pauta-se numa implicação pragmática, a de que os nordestinos

\footnotetext{
${ }^{1}$ No Brasil, o racismo é crime inafiançável e imprescritível (cf. Artigo $5^{\circ}$ da Constituição Federal de 1988). A injúria, que é o caso de a ofensa ser dirigida a um indivíduo específico do grupo e não ao grupo como um todo (o que seria racismo), é tipificada pelo Código Penal Brasileiro, Art. 140. No § 3 , lê-se que o ofensor pode cumprir pena, de três meses a um ano, "[s]e a injúria consiste na utilização de elementos referentes a raça, cor, etnia, religião, origem ou a condição de pessoa idosa ou portadora de deficiência” (redação dada pela Lei no 10.741 , de 2003).
} 
foram os responsáveis pela eleição da candidata petista. Como é o caso com a maioria dos preconceitos, essa implicação não tem fundamento lógico, uma vez que não foi propriamente o voto do Nordeste que pesou a balança para o lado de Dilma. Mesmo que se extraíssem os votos do Nordeste do cômputo geral, Dilma haveria sido eleita, sobretudo devido ao número massivo de votos para ela no Rio de Janeiro e em Minas Gerais, os dois maiores colégios eleitorais brasileiros depois de São Paulo.

É importante observar que o enunciado ecoado por Mayara não foi o único naquele momento. A Internet brasileira foi palco de uma verdadeira avalanche de ditos injuriosos. Por exemplo, o usuário de Twitter Clayton Americo declarou: "Bem vou trabalhar porque não ganho Bolsa Família dos Nordestinos. Nem faço 2 filhos por ano pra ter bolsa família"; uma usuária que se identificava como Fer Leoni afirmou: "Para eleitores de merda, uma presidente de merda"; no Twitter de LC Gasparello lia-se "Parabéns eleitor, o norte/nordeste elegeu uma presidente e o sul/sudeste tem que trabalhar para sustentar essa camada de vagabundos", dentre tantos outros. Na mídia corporativa, liam-se artigos como o do jornalista Leandro Nardoch, que afirmava: "os nordestinos, grupo que garantiu a vitória da candidata petista nas eleições" (Folha de S. Paulo, 11/11/2010). O jornal O Estado de S. Paulo publicou no dia seguinte às eleições um mapa em que as regiões do Brasil foram coloridas de acordo com as cores das bandeiras do PT e do PSDB, vermelho e azul, respectivamente. Via-se, assim, uma grande concentração de diferentes tons de vermelho de Minas Gerais até o Amapá e do norte do Maranhão até o Amazonas; a concentração de azul, por outro lado, era maior nas regiões Sul, Sudeste e Centro-Oeste.

O fato de Mayara ter enunciado o dito injurioso num contexto tão amplo de atos de fala semelhantes mostra que ela estava, de algum modo, repetindo condições prévias injuriosas. Em artigo intitulado "Em defesa da estudante Mayara", Janaína Conceição Paschoal, professora de direito penal na famosa escola do Largo de São Francisco, chegou a afirmar que o originador da cisão entre Norte e Sul seria o próprio então presidente Lula: "É o nosso presidente quem faz questão de separar o Brasil em Norte e Sul. É ele quem faz questão de cindir o povo brasileiro em pobres e ricos" (Folha de S. Paulo, 12/11/2012). Mas será que o fato de os ditos violentos serem sempre certa repetição de uma sinuosa e difusa cadeia de atos de fala isenta de responsabilidade aquele que os repete? Se o sujeito nunca pode ser considerado de fato o originador do dizer, o que fazer então com as palavras violentas, que extraem sua força ilocucional injuriosa da repetição? A decisão da $\mathrm{OAB} / \mathrm{PE}$ reflete uma maneira como, no mundo prático, a responsabilidade sobre a fala injuriosa pode ser tratada. Numa espécie de congelamento da história, a instituição interpretou que a ação por racismo devia ser movida contra Mayara e não contra todos aqueles que se manifestaram preconceituosamente no dia porque "foi ela quem começou" (Yahoo! Brasil, 3/11/2010). A violência expressa no dizer da estudante de direito - que talvez de modo jocoso, talvez não, convidava que se matasse um nordestino afogado como favor a São Paulo - precisava ser combatida de algum modo, e a estrutura de punição do Direito parecia ser um modo eficaz. 
A ficção retrospectiva da $\mathrm{OAB}$, que atribuía acontabilidade a Mayara pelo dito injurioso, parecia assim "paralisar a história" e atribuir um valor de prototipicidade ao caso. "O objetivo da ação contra Mayara, segundo a OAB-PE, é acabar com a percepção que existe de que manifestações odiosas na internet acabam impunes" (Yahoo! Brasil, 3/11/2010).

Não podemos perder de vista, no entanto, que a violência na linguagem ali era um fato mediado. Um amplo processo de mediação circundou os atos de fala injuriosos em questão. Nele estavam envolvidos jornalistas, advogados e a própria sociedade civil usando a fala e a escrita em diferentes gêneros e em diferentes lugares. Acreditamos que observar a mediação (e não meramente a 'media') pode ser uma chave para entender melhor a violência que emergia daquelas palavras. Antes de passarmos para uma consideração metodológica sobre como investigar a violência como fato mediado, vejamos uma definição de mediação semiótica de uso corrente em pragmática e antropologia linguística:

A vida social assume um caráter mediado a cada vez que as pessoas se unem umas às outras pela fala ou por meio de outros signos perceptíveis em quadros de participação de atividade comunicativa. Tais elos envolvem diferentes limiares de relacionamento: enunciados falados mediam relações entre comunicadores co-presentes; artefatos impressos, a grandes distâncias de tempo e espaço; tecnologias eletrônicas, em graus variados de consciência mútua, de direcionalidade de contato e de possibilidades de reciprocidade. Falar de mediação comunicativa é observar que os signos comunicativos formulam uma conexão entre aqueles por eles unidos, mediando relações sociais por meio de atividades de apreensão e resposta em diferentes escalas na história social (Agha, 2011:163).

A mediação comunicativa ou semiótica é, portanto, aquilo que estabelece o laço social entre os falantes, um laço que é mediado pela linguagem toda vez "que as pessoas se unem umas às outras pela fala ou por meio de outros signos perceptíveis". E a violência na linguagem, por meio de uma pragmática e uma metapragmática específicas, rompe ou reconfigura esse laço.

De forma a entendermos a mediação semiótica da violência linguística que emergia das palavras de Mayara, fizemos entrevistas com jornalistas, advogados e nordestinos nas cidades do Rio de Janeiro, São Paulo, Recife e Fortaleza. Observamos sobretudo interações em que migrantes do Nordeste na cidade do Rio de Janeiro posicionavam-se diante do acontecido e de como aquele fato se relacionava com sua condição de migrantes. Essa incursão etnográfica tem sido pautada por momentos de interação eloquentes, como foi nossa conversa com o autor do habeas corpus de Mayara Petruso, Pedro Costa ${ }^{2}$. Fomos bem recebidos pela $\mathrm{OAB}$ de Pernambuco, autora da ação contra Mayara. Alguns silêncios significativos também constituem a história desse estudo, como foi o caso, por exemplo, da indisponibilidade do juiz responsável pelo caso em falar conosco. De algum modo, trata-se de um silêncio já esperado, em vista de os juízes corriqueiramente se manifestarem publicamente sobre um processo apenas depois que uma sentença é pronunciada.

${ }^{2}$ Por motivos éticos, todos os nomes de participantes no estudo etnográfico foram substituídos por nomes fictícios. 
Em dezembro de 2011, um bolsista de iniciação científica e Daniel sentamos num café na Livraria Travessa, no Centro do Rio, para conversar com Pedro Costa, autor do habeas corpus que permitiu que Mayara Petruso seja julgada em liberdade. Pedro é um homem branco, na faixa dos 30 anos. Ele vestia um terno escuro e sentou-se conosco à mesa bastante suado, num dia bastante quente daquele verão. Durante toda a conversa, Pedro tentou nos convencer de algumas teses, que oportunamente contrastaremos com a de outros especialistas em direito. A primeira das teses é a de que Mayara não estava se referindo aos nordestinos, mas aos eleitores de Dilma. Diz ele:

Nós sabemos o que é um significante, o que é um significado e o que é um signo
linguístico. A mulher usou ali o termo "nordestino". Agora o que que ela quis
dizer com nordestino? Será que era o cidadão brasileiro que nasce no nordeste,
algum daqueles nove estados? Ou ela queria dizer "eleitor da Dilma", baseada no
estereótipo de que os nordestinos votam em peso no PT? Então ali seria uma crítica
política. Ela queria dizer "mate um eleitor da Dilma". É claro que não tinha como
sair exterminando eleitor da Dilma Brasil afora. O que temos aí como "matar"?
Mesmo "matar afogado" admite interpretações. O Nietzsche por exemplo chamava,
"eu gosto do homem que deseja perecer". Ele tá elogiando o suicídio? Não. Ele tá
elogiando a superação de si.

Há na fala de Pedro um desreconhecimento (Bourdieu, 1991) do preconceito contra os nordestinos estampado nas palavras de Mayara. E isso é sustentado na fala dele por alguns modos de conceber a linguagem. As chamadas ideologias de linguagem (Silverstein, 1979) implicam certos modos de entender os usos e funções da língua e são parte indissociável da experiência de qualquer usuário da língua. Pedro invoca inicialmente a teoria do signo de Saussure. Observe-se que a referência aos termos 'significado', 'significante' e 'signo linguístico' não articula logicamente a teoria saussuriana com a tese que ele queria defender; a menção a Saussure estabelece, ao contrário, uma implicação pragmática: o especialista sabia estar diante de um professor de Linguística e de um aluno de Letras e procurava, nesse sentido, estabelecer um sentimento de saber partilhado. Note-se que ele inclusive usa o 'nós' para tentar estabelecer ali uma comunidade.

Podemos afirmar grosseiramente que a ideologia de linguagem em questão soma a ideia de que 'na linguagem há signos' e a de 'Nietzsche empregou metáforas' de forma a sustentar pragmaticamente a tese de que Mayara não fez o que fez, isto é, de que, ao se referir ofensivamente aos nordestinos, ela estava fazendo outra coisa. Uma hipótese relativamente comum na literatura sobre a relação entre violência e suas formas simbólicas é que a violência na linguagem tende a não ser reconhecida como tal. Judith Butler, por exemplo, postula que nenhum termo fere sem uma "dissimuladora e acumuladora historicidade da força" (1997:51, ênfase acrescida). Allen Feldman apontou que violência política na Irlanda do Norte produz sujeitos através de atos específicos de violência (visual). A violência do olhar militar na Irlanda do Norte faz interseção com a masculinidade e escamoteia suas próprias condições de produção: o olhar masculino naturaliza a construção política do seu "aparato perceptual" e se exibe como "natural, imutável e a-histórico" 
(Feldman, 2000:62). Pierre Bourdieu, por seu turno, defende que a violência simbólica é "forma de violência sutil e invisível que nunca é reconhecida como tal" (1977:192).

Além do desreconhecimento, a violência na linguagem também depende do modo como o discurso se sustenta pragmática e metapragmaticamente. A pragmática, o modo como os signos são usados no mundo, anda lado a lado com a metapragmática, o modo como os signos representam esse estar-no-mundo. Nos termos de Silverstein (1993), todo signo é, em si, um signo pragmático, na medida em que seu uso "indexa um contexto ou uma circunstância". A compreensão dos signos como objetos indiciais é modelada ou regimentada pela metapragmática do discurso. Para usar a expressão de Gumperz (1982), o discurso em interação geralmente oferece "pistas contextuais": a fala e a escrita sinalizam o modo como as partes do discurso devem ser compreendidas, que caminho os interactantes devem seguir, quando mudar o turno, quando encerrar a conversa etc. Silverstein (1993:36-37) afirma que, numa interação discursiva, "sem uma função metapragmática simultaneamente em jogo com a função pragmática" não haveria coerência interacional. A “armadura" metapragmática é o que permite ao autor do habeas corpus voltar-se aos signos violentos de Mayara e legitimá-los, de forma tanto a desreconhecer o crime de racismo quanto a engendrar outros signos violentos. Ao ser perguntado sobre o peso do enunciado "Faça um favor a SP, mate um nordestino afogado", Pedro responde:

Olha, eu acho que isso daí a rigor, ela tá refletindo um pensamento até geral do brasileiro. As pessoas dizem isso. Elas sempre falaram coisas assim. E não só nordestino. É comum a gente encontrar na Internet ou até mesmo pixado em muro coisas como "mantenha Salvador limpa, mate um veado todo dia".

Perceba-se que a referência de Pedro à pichação "comum" nos muros de cidades como Salvador é feita como uma forma de 'menção' e não como 'uso'. Lembremos da distinção que Frege estabelece entre uso e menção: quando empregamos uma palavra "de modo corrente", então estamos usando a palavra, e nosso objetivo é a "referência"; ao colocarmos a palavra entre aspas, estamos fazendo uma menção (1894:64), nosso objetivo é a intensão da expressão, o seu "sentido". Na menção, postula Frege, "a palavra (...) não deve ser tomada como tendo sua referência usual" (ibidem). Mas, no caso das palavras que ferem, essa distinção não se sustenta: a menção ao termo violento acaba se tornando uma nova instância de uso. Numa concepção matemática de linguagem, é possível esvaziar a menção de seu conteúdo semântico usual. Por outro lado, se abandonamos a hipótese de que a linguagem espelha o mundo, a menção de um termo passa a ter um valor performativo: mencionar um termo violento pode ter diferentes forças ilocucionais (e.g., em psicanálise, a menção a uma experiência traumática pode ter o valor performativo de cura).

Tanto na fala quanto no habeas corpus, impetrado na Justiça Federal de São Paulo, Pedro Costa evoca a noção de intenção, a que ele se refere pela palavra latina 'animum'. No texto do habeas corpus, lê-se que o dizer de Mayara 'era apenas manifestação de animus jocandi". Trata-se do mesmo argumento invocado anteriormente, o de que Mayara estaria "apenas brincando", sua "intenção" era 
brincar. Embora de fato a intenção seja uma figura que anime várias categorias do direito penal, há momentos em que essa noção perde o peso. Esse pareceu ser o entendimento da OAB. João Studart, especialista da instituição que participou da redação do processo contra Mayara, nos disse que "alegar que ela não teve a intenção, que foi apenas uma piada é um argumento muito frágil”. A noção de intenção, nas teorias da significação, opera de acordo com a 'espiritualização' dos conceitos, segundo Wittgenstein. Quando não se pode (ou não se quer) explicar a natureza de um enunciado a partir de sua realidade concreta na interação, apelase para uma noção interior e espiritual como a de intenção. Mas vejamos que o argumento de João é exatamente no sentido da concretude dos atos de fala. Diz o advogado:

Eu acho que a gente tem o direito de liberdade de expressão, desde que essa liberdade não seja um instrumento de violação de direitos. No momento em que ela exerceu o direito de liberdade de expressão e ao mesmo tempo violou o direito da dignidade humana dos nordestinos, aquele direito de liberdade de expressão deve ser limitado. Nenhum direito previsto na constituição é absoluto, (...) ela tava no exercício direito de liberdade de expressão até o momento em que ela violou a dignidade humana. Nesse momento foi configurado o crime, não importa se ela tinha a intenção, o dolo, porque promoveu o ato criminoso e tem que ser responsabilizada.

De acordo com João, a liberdade de expressão encontra seu limite na violação da dignidade humana. Mayara cometeu um ato criminoso na linguagem, e esse ato foi superior à intenção. Não importa se ela teve ou não a intenção de ferir - as palavras de seus perfis da Internet veiculavam ofensas à dignidade dos nordestinos e foram justamente as palavras, e não as intenções, que nortearam a noção de responsabilidade a partir da qual a acusação moveu sua ação no Ministério Público Federal.

Comenta Charles Briggs (2007b:552) que algumas práticas linguísticas modernas ganham poderes quase mágicos de figurarem como "recipientes transparentes de crenças, experiências e atitudes". Briggs tem tentado demonstrar, a partir do conceito de comunicabilidade (2007a, 2007b e 2011), que há um processo amplo de mediação e naturalização dos discursos que opera mais ou menos como os vírus ou bactérias. Uma das definições de 'comunicável' em português é justamente aquilo "que se propaga com facilidade, que é contagiante" (cf. Houaiss). Na vida social, certos discursos infectam modos de ver o mundo e conferem diferentes graus de agência e adesão a ideologias, projetando formas de compreensão e recepção. Esse processo de naturalização pode, no entanto, ser contestado - e foi precisamente de advogados nordestinos que escutamos críticas a esse movimento quase mágico das palavras que ferem. Assim, João Studart afirmou que "as pessoas têm ideia de que a Internet, os perfis de Facebook etc. são ambiente de irresponsabilidade. Mas as atitudes ali têm um alcance muito grande, uma força muito grande e devem ser responsabilizadas." Santiago Lima, advogado da cidade de Fortaleza, alertou que mensagens na Internet "têm uma disseminação e abrangência muito maior do que um comentário com um colega ou com um amigo. Porque quando você comenta pela Internet ou numa dessas 
ferramentas tecnológicas novas como Twitter, Facebook, você tá alcançando uma gama muito grande de pessoas." O especialista de Fortaleza alertou que "muito pouco se questionou por que aquela moça optou por fazer uma distinção entre dois segmentos do Brasil. Como se alguma delas fosse superior ou inferior, digamos assim." Ele aponta que as conexões naturalizadas entre nordestinos e "povo empobrecido, povo rude", que por tanto tempo ficaram "latentes, escondidas entre a sala de estar e a cozinha da classe média brasileira" e agora chegavam ao domínio publico através da Internet, precisam ser questionadas.

Segundo Santiago, quando o "direito cuida do crime, é aquilo que a sociedade mais repudia como infame, incorreto, ilícito, não querido por essa mesma sociedade." Há nos termos dele um fundo sociológico maior que deve ser invocado quando crimes de ódio como o de Mayara são cometidos. Então, aquilo que a defesa de Mayara aponta como "as pessoas dizem isso. Elas sempre disseram isso" e que constitui, a nosso ver, uma naturalização do movimento comunicável dos discursos, é visto pelos advogados nordestinos ora como um movimento que precisa ser capturado retrospectivamente e penalizado (como foi o caso da ação da $\mathrm{OAB} / \mathrm{PE}$ ), ora como algo que está na ponta de um iceberg sociológico, a lei criminal sendo apenas o ápice daquilo que é mais repudiado socialmente. "Precisamos buscar as razões sociológicas", repetiu enfaticamente Santiago Lima.

\section{PALAVRAS FINAIS}

Em maio de 2012, Mayara Petruso foi condenada pela Justiça Federal de São Paulo a 1 ano, 5 meses e 15 dias de prisão pelo crime de racismo. Como a estudante era ré primária, a pena foi convertida em serviços à comunidade. Esta foi a primeira condenação por crime de racismo cometido em uma mídia social. Para retomarmos os termos de João Studart, trata-se certamente de uma decisão judicial exemplar, que ajudará a circunscrever os ambientes virtuais como espaços de responsabilidade.

A culpabilidade estabelecida pela justiça, que isolou uma "autora" diante de um emaranhado difuso de invectivas racistas e intolerantes, tem uma função a um só tempo reguladora e pedagógica. Que as palavras ferem e que os limites da liberdade de expressão são os direitos à dignidade do humano foram parâmetros que esta sentença ajudou a disseminar.

Para além da estrutura de acontabilidade do direito, porém, o que podemos depreender da circulação dessas palavras de ódio, da machucabilidade sentida por muitos nordestinos e da resposta igualmente irada e violenta de alguns nordestinos (para quem, numa inversão absurda do preconceito, um paulista devia ser afogado) é que conflito e impolidez não são propriamente "falhas pragmáticas", mas modos em que a língua é usada não-cooperativamente, para ofender, ferir, injuriar, machucar. Conforme discutimos na seção 2, a ontologia vitalista amplamente presente nos estudos da linguagem tem impedido que muitos teóricos deem a devida atenção às interações conflituosas. Geoffrey Leech (1983:105) postulou, num dos primeiros manuais de pragmática, que "ilocuções conflitivas tendem a 
ser, felizmente, bastante marginais no comportamento linguístico humano em circunstâncias normais". O enunciado de Leech não só se funda na perspectiva vitalista, como também ecoa o legado de Noam Chomsky de observar o "normal" ou "ideal" da língua. A prática linguística "real" e "não-ideal", no entanto, aponta para um cenário radicalmente diferente, o que demanda do/a linguista teorias e ferramentas igualmente diferentes.

Se é certo que o direito à dignidade e à igualdade é uma conquista básica dos direitos humanos - uma noção bastante recente, diga-se de passagem -, a garantia desses direitos requer atenção aos diversos mecanismos da língua que são empregados para violar a condição universalmente humana do usuário da língua. Entendemos que tornar visíveis os múltiplos modos em que a língua é usada para depreciar, ofender, ferir ou violentar aquele ou aquela que ocupa o lugar que não se quer habitar pode significar um gesto de combater esses modos de violação e, em última instância, uma visada emancipatória e afirmativa dentro dos estudos da linguagem.

\section{$\overline{\text { REFERÊNCIAS BIBLIOGRÁFICAS }}$}

ADORNO, S. (2011) Violência e crime: sob o domínio do medo na sociedade brasileira. In: BOTELHO, A. et al. (Org.). Agenda Brasileira: Temas de uma Sociedade em Mudança. São Paulo: Cia. das Letras, pp. 554-565.

AGHA, A. (2011) Meet mediatization. Language \& Communication 31:163-170.

ASAD, T. (2003) Formations of the secular: Christianity, Islam, Modernity. Stanford: Stanford University Press.

. (2008) Reflections on blasphemy and secular criticism. In: de Vries, H. (Ed.) Religion: Beyond a concept. Fordham: Fordham University Press, pp.580-609.

AUSTIN, J. (1962) How to do things with words. Cambridge: Harvard University Press.

BOURDIEU, P. (1977) Outline of a Theory of Practice. Trad. Richard Nice. Cambridge: Cambridge University Press.

. (1991) Language and symbolic power. Trad. G. Raymond \& M. Adamson. Cambridge: Harvard University Press.

BOUSFIELD, D. (2008) Impoliteness in interaction. Amsterdam: John Benjamins.

BOUSFIELD, D. \& M. Locher (Orgs.) (2008) Impoliteness in Language: Studies on its Interplay with Power in Theory and Practice. Berlin: Mouton de Gruyter.

BRIGGS, C. (2007a) Mediating infanticide: Theorizing relations between narrative and violence. Cultural Anthropology. 22(3):315-316.

. (2007b) Anthropology, interviewing, and communicability in contemporary social life. Current Anthropology, 48(4):551-580.

. (2011) On virtual epidemics and the mediatization of public health. Language \& Communication 31:217-228.

BROWN, P. \& S. Levinson (1987 [1978]) Politeness: Some Universals in Language Usage. Cambridge: Cambridge University Press. 
BUTLER, J. Excitable speech: a politics of the performative. London: Routledge, 1997.

CAldEIRA, T. (2000) City of Walls: Crime, segregation and citizenship in São Paulo. Berkeley: University of California Press.

Cottingham, J. (1995) Dicionário Descartes. Trad. Helena Martins. Rio de Janeiro: Zahar.

CULPEPER, J. (2011) Impoliteness: Using Language to Cause Offence. Cambridge: Cambridge University Press.

CHEAH, P. (1999) Spectral nationality: The living on [sur-vie] of the postcolonial nation in neocolonial globalization. Boundary 2, 26(3):225-252.

DERRIDA, Jacques (1977) Signature Event Context. Trad. Samuel Weber \& Jeffrey Mehlam. Glyph. 1: 172-197.

. (1973) Gramatologia. Trad. Miriam Chnaiderman e Renato Janine Ribeiro. São Paulo: Perspectiva.

FELDMAN, Allen (2000) Violence and vision: The prosthetics and aesthetics of terror. In: Das, V. et al. (Orgs.) Violence and subjectivity. Berkeley: University of California Press, pp. 46-78.

FOUCAULT, Michel (1998[1969]) What is an author? In: Faubian, J. (Org.) Aesthetics, Method and Epistemology. New York: The New Press, pp. 205-222.

FREGE, G. (1978[1894]) Sobre o sentido e a referência. In: Alcoforado, P. (Org.) Lógica e filosofia da linguagem. São Paulo: Cultrix, pp. 59-86.

FREUD, S. (1997[1930]) O mal-estar na civilização. Trad. de José Octávio de Aguiar Abreu. Rio de Janeiro: Imago.

GIBBS Jr., R., Lima, Paula L. C \& E. Françozo (2001) Metaphor is grounded in embodied experience. Journal of Pragmatics, 36: 1189-1210.

GRADY, J. (1997) Foundations of meaning: primary metaphors and primary scenes. Tese de doutorado, University of California, Berkeley.

GRICE, P. (1975) Logic and conversation. In: Cole, P. \& J. Morgan (Orgs.) Syntax and Semantics 3: Speech Acts. London: Academic Press, pp.41-58. . (1989) Studies in the Way of Words. Cambridge: CUP.

GUMPERZ, John. Discourse strategies. Cambridge: Cambridge University Press, 1982.

HANKS, William. Language form and communicative practices. In: GUMPERZ, John \& LEVINSON, Stephen (Orgs.) Rethinking Linguistic Relativity. Cambridge: Cambridge University Press, 1996.

JING-SCHMIDT, Z. (2007) Negativity bias in language: A cognitive-affective model of emotive intensifiers. Cognitive Linguistics, 18(3):417-443.

KELLY, M. (2000) Naming on the bright side of life. Names, 48(1), 3-26.

LAKOFF, George. (1987) Women, fire, and dangerous things. Chicago: Chicago University Press.

LEECH, G. (1983) Principles of Pragmatics. London: Longman. 
LEVINSON, S. (1983) Pragmatics. Cambrige: Cambrige University Press.

LIMA, P. (1999) Desejar é ter fome: novas idéias sobre antigas metáforas conceituais. Tese de doutorado, Campinas, Unicamp.

RAJAGOPALAN, Kanavillil. Sobre o porquê de tanto ódio contra a linguagem politicamente correta. In: SILVA, Fábio \& MOURA, Heronides (Orgs.) O direito à fala: a questão do preconceito linguístico. Florianópolis: Insular, 2000, pp. 93-111.

SCHEPER-HUGHES, Nancy \& P. Bourgois (2004) Introduction: Making sense of violence - the violence continuum. In: Scheper-Hughes, N. \& Bourgois, P. (Orgs.) Violence in war and peace. Malden: Blackwell, pp. 1-31.

SILVERSTEIN, M. (1979) Language Structure and Linguistic Ideology. In: Clyne, P., W. Hanks \& C. Hofbauer (Orgs.) The Elements: A Parasession on Linguistic Units and Levels. Chicago: Chicago University, pp. 193-247.

. (1993) Metapragmatic discourse and metapragmatic function. In: LUCY, John (Org.) Reflexive language: Reported speech and metapragmatics. Cambridge: Cambridge University Press, pp. 33-58.

. (2003) Indexical Order and the Dialectics of the Sociolinguistic Life. Language \& Communication 23: 193-229.

WITTGENSTEIN, Ludwig (1953) Philosophical Investigations. Trad. G. E. M. Anscombre. Oxford: Blackwell. 